\title{
SERVIÇO SOCIAL, ARTE E HUMANIZAÇÃO: OLHAR DAS MÃES SOBRE A VISITA DOS PALHAÇOS NA PEDIATRIA
}

SOCIAL WORK, ART, AND HUMANIZATION: MOTHERS' VIEW ON CLOWNS VISITING THE PEDIATRIC SERVICE

TRABAJO SOCIAL, ARTE Y HUMANIZACIÓN: LA OPINIÓN DE LAS MADRES SOBRE LOS PAYASOS QUE VISITAN EL SERVICIO

PEDIÁTRICO

Francisca Leyla da Silva Morais ${ }^{1}$

Angélica Maria Barbosa ${ }^{2}$

Fátima Maria Coelho Bezerra Bastos 3

Renata Lima da Costa 4

Palavras-chave:
Serviço Social; Arte; Humanização da
Assistência.

Keywords:

Social Work; Art; Humanization of

Assistance

Palabras clave:

Servicio Social; Arte; Humanización

de la Atención.

Submetido: 26 de Set. de 2019

Aprovado: 11 de Nov. de 2020

Autor(a) para Correspondência: Francisca Leyla da Silva Morais R. 1060, 89 Conjunto Ceará Fortaleza, CE. CEP: 60533-050

E-mail: leylamorais.as@gmail.com

\section{RESUMO}

A hospitalização de uma criança altera o equilíbrio de uma família, que precisa reorganizar-se em torno da recuperação dela, sendo a mãe normalmente o membro familiar que acompanha a criança no hospital. Este estudo teve por objetivo elucidar os potenciais da arte em processos de humanização dos serviços de saúde, por meio do olhar das mães com filhos internados. Trata-se de pesquisa-ação com abordagem qualitativa, tendo como cenário o Setor de Pediatria do Hospital de Messejana "Dr. Carlos Alberto Studart Gomes" (HM), em Fortaleza-CE. A coleta de dados consistiu na realização de entrevistas, posteriormente gravadas e transcritas até a saturação dos dados. Os dados foram submetidos a Análise de Conteúdo de Bardin. A amostra consistiu em 12 mães. Os resultados foram organizados em 3 categorias temáticas: a) Hospitalização infantil; b) Humanização do atendimento hospitalar; e c) Visita do Projeto Trupe Sorriso. Concluiu-se ser primordial que haja sensibilização quanto à problematização da realidade, a partir da equipe multidisciplinar de saúde, e ao aprofundamento do tema para esclarecer as dúvidas das mães sobre o assunto.

1. Especialista em Impactos da Violência na Saúde pela Fundação Oswaldo Cruz (FioCruz). Especialista, na modalidade Residência em Saúde, em Cardiopneumologia pela Escola de Saúde Pública do Ceará (ESP/CE). Preceptora do Programa de Residência Integrada em Saúde (RIS) da ESP/CE. E-mail: leylamorais.as@gmail.com ORCID: https://orcid.org/0000-0002-9768-9857

2. Mestre em Saúde da Criança e do Adolescente pela Universidade Estadual do Ceará (UECE). Especialista em Família: Abordagem Sistêmica. ela Universidade de Fortaleza (Unifor). Especialista em Gestão do Potencial Humano nas Organizações pela Unifor. E-mail: ambarbosa@uol.com.br 0RCID: https://orcid.org/0000-0003-4183-942X

3. Mestre em Saúde da Criança e do Adolescente pela Universidade Estadual do Ceará (UECE). Bacharel em Direito pelo Centro Universitário Christus (UniChristus). Preceptora da Residência Multiprofissional, com ênfase em Cardiopneumologia, do Hospital de Messejana “Dr. Carlos Alberto Studart Gomes" (HM). E-mail: fatimacbastoshm@ gmail.com ORCID: https://orcid.org/0000-0002-2375-6228

4. Mestre em Avaliação de Políticas Públicas pela Universidade Federal do Ceará (UFC). Especialista em Serviço Social, Políticas Públicas e Direitos Sociais pela UECE. Preceptora do RIS da ESP/CE. E-mail: renata.l.costa@gmail. com ORCID: https://orcid.org/0000-0002-3291-4662

Certificação de redação científica: E.L.Freire Editora. Edição de texto: Evandro L. Freire. Revisão de provas: Texto definitivo lido e validado pelas autoras. 


\section{ABSTRACT}

A child's hospitalization changes the balance of a family, which needs to reorganize itself towards the child's recovery, and the mother is usually the family member accompanying the child to the hospital. This study aimed to elucidate the potentials of art in humanization processes in health services, through the eyes of mothers with hospitalized children. This is an action research with a qualitative approach, whose scenario was the Pediatric Service of Messejana's Hospital 'Dr. Carlos Alberto Studart Gomes' (Hospital de Messejana [HM]), in Fortaleza, Ceará, Brazil. Data collection consisted of interviews, which were subsequently recorded and transcribed until data saturation. Data underwent Bardin's Content Analysis. The sample consisted of 12 mothers. The results were organized into 3 thematic categories: a) Child hospitalization; b) Humanization of hospital care; and c) Visit of the 'Trupe Sorriso' Project. We concluded that it is key to raise awareness about the discussion of reality, having the multidisciplinary health team as a basis, and to deepen the theme in order to clarify mothers' doubts about the subject.

\section{RESUMEN}

La hospitalización de un niño cambia el equilibrio de una familia, que necesita reorganizarse para su recuperación, y la madre suele ser el miembro de la familia que acompaña al niño en el hospital. Este estudio tuvo como objetivo dilucidar las potencialidades del arte en los procesos de humanización en los servicios de salud, a través de la mirada de madres con hijos hospitalizados. Se trata de una investigación-acción con abordaje cualitativo, cuyo escenario fue el Servicio de Pediatría del Hospital de Messejana "Dr. Carlos Alberto Studart Gomes" (Hospital de Messejana [HM]), en Fortaleza, Ceará, Brasil. La recolección de datos consistió en entrevistas, que posteriormente fueron grabadas y transcritas hasta la saturación de datos. Los datos se sometieron al Análisis de Contenido de Bardin. La muestra estuvo compuesta por 12 madres. Los resultados se organizaron en 3 categorías temáticas: a) Hospitalización infantil; b) Humanización de la atención hospitalaria; y c) Visita del Proyecto "Trupe Sorriso". Concluimos que es clave concienciar sobre la discusión de la realidad, teniendo como base al equipo multidisciplinario de salud, y profundizar el tema para aclarar las dudas de las madres sobre el tema.

\section{INTRODUÇÃ 0}

As conquistas e os avanços nos debates e enfrentamentos no âmbito das políticas públicas de saúde observados no Brasil desde a implantação do Sistema Único de Saúde (SUS), como exposto na Constituição Federal (CF) de 1988, têm sido matériaprima das mais diferenciadas discussões no campo do serviço social, tanto referentes aos delineamentos políticos, sob a perspectiva de definir e defender um posicionamento em torno do projeto da reforma sanitária, quanto às inquietações que envolvem a criação e alteração de modelos assistenciais, o trabalho do assistente social e os diferentes temas que emergem de sua inserção no setor saúde ${ }^{1,2}$.

0 tema humanização da assistência em saúde se mostra importante no contexto atual, uma vez que a adoção de um atendimento balizado em princípios como a integralidade da assistência, a equidade e a participação social dos usuários ${ }^{3}$, dentre outros, demanda constante revisão das práticas cotidianas, com ênfase na criação de espaços de trabalho menos alienantes que valorizem a dignidade dos profissionais e dos usuários ${ }^{4}$.

Buscar formas efetivas para humanizar as práticas em saúde implica aproximação crítica que possibilite compreender o tema para além de seus componentes técnicos e instrumentais, envolvendo, essencialmente, suas dimensões político-filosóficas que the conferem sentido.

Segundo a Carta dos Direitos dos Usuários da Saúde ${ }^{5}$ e a Política Nacional de Humanização $(\mathrm{PNH})^{6}$, trata-se de direito dos cidadãos contar com atendimento acolhedor na rede de serviços de saúde, de modo humanizado e livre de qualquer discriminação, restrição ou negação, assegurando um atendimento que respeite seus valores durante o tratamento.

Humanizar a assistência é uma preocupação constante dos profissionais da saúde em geral. Para tanto, tem-se buscado aprimorar as práticas de cuidado, adotando novos modelos assistenciais nos quais a equipe multidisciplinar não se preocupe apenas com a doença, mas com o ser humano como um todo6,7. Para tal mudança de prática se faz necessário conhecer o olhar dos usuários sobre a 


\section{Humanizar a assistência é uma preocupação constante dos profissionais da saúde em geral.}

humanização do atendimento hospitalar, entendendo e identificando o que eles sabem sobre o assunto. Isso viabiliza a elaboração de uma proposta de atendimento humanizado onde as dúvidas sejam esclarecidas de modo mais específico ${ }^{8}$.

Ao longo da história, a arte tem instigado emoções e provocado as reações mais diversas, como experimentar sensações e expressar questões de grande relevância para o ser humano em formato singular e universal, inclusive na garantia de direitos $^{9}$. À medida que a vida humana se fragmenta pela complexidade de tarefas e interesses, mais se consolida a função da arte: refundir o homem consigo ${ }^{10}$.

Os efeitos terapêuticos da arte têm sido reconhecidos há alguns séculos e, nas últimas décadas, foram desenvolvidos estudos científicos sistemáticos que objetivaram, sobretudo, compreender os efeitos da arte sobre a saúde dos pacientes.

Assim, esta pesquisa partiu da experiência do Projeto Trupe Sorriso, com ações de humanização realizadas por residentes multiprofissionais em saúde, por meio de visitas com palhaços doutores em unidades de pediatria hospitalar, mediante a implementação de um projeto de palhaçoterapia e, ainda, em manifestações de música e teatro nas enfermarias. Essa experiência despertou o interesse pelo aprofundamento teórico e prático em torno da relação entre a humanização e a arte no contexto da pediatria por meio da seguinte questão:

- Qual é o olhar de mães com filhos hospitalizados sobre a presença dos palhaços doutores na pediatria hospitalar?

Este estudo teve por objetivo elucidar os potenciais da arte em processos de humanização dos serviços de saúde, por meio do olhar das mães com filhos internados em unidade de pediatria hospitalar.

\section{METODOLOGIA}

Trata-se de pesquisa-ação com abordagem qualitativa. 0s participantes foram as mães ou as responsáveis legais pelas crianças (indivíduos de até 12 anos de idade, como previsto pelo Estatuto da Criança e do Adolescente [ECA]) ${ }^{11}$ que estiveram internadas na Unidade de Pediatria, do Hospital de Messejana “Dr. Carlos Alberto Studart Gomes" (HM), em Fortaleza-CE, no período de junho a agosto de 2018.

A unidade de pediatria é um serviço de internação responsável pela assistência integral à criança e ao adolescente com doença cardíaca de alta complexidade, realizando inclusive transplantes cardíacos nos referidos pacientes, tanto junto a moradores do município quanto do interior do estado, que chegam à instituição para realizar diversos tipos de procedimentos.

A amostra da pesquisa teve como critérios de inclusão: a) ser mãe ou responsável legal da criança que esteve internada na unidade de pediatria do HM, no período da coleta de dados; b) falar e compreender a língua portuguesa; e c) aceitar participar do estudo mediante convite. Já os critérios de exclusão foram: a) ser menor de idade, sem consentimento da responsável legal; b) mães cujos filhos estiveram internados na unidade de terapia intensiva (UTI), por não se encontrarem em condições clínicas estáveis.

A coleta de dados foi realizada por meio de 7 visitas dos integrantes do Projeto Trupe Sorriso, no período de março a maio de 2018, com duração de 50 minutos a 1 hora cada, usando estratégias de arte com teatro, música e artifícios lúdicos. As visitas ocorreram nas enfermarias e nos corredores, espaços ao lado das enfermarias onde crianças maiores, com condições clínicas favoráveis, podem usar o ambiente. No início da pesquisa foram convidadas a participar do estudo todas as mães que acompanhavam seus filhos no internamento e que cumpriam os critérios de inclusão e exclusão da amostra - ao todo, 15 mães foram convidadas e 12 aceitaram participar, constituindo a amostra final da pesquisa.

Essas mães foram convidadas no setor de pediatria e a pesquisadora responsável pela entrevista explicou para elas a proposta da pesquisa. Em seguida, o termo de consentimento livre e esclarecido foi lido e assinado, garantindo-se o sigilo e anonimato das participantes.

Durante as visitas os dados foram coletados por meio de entrevistas semiestruturadas, seguindo um roteiro pré-elaborado que continha dados demográficos e socioeconômicos das participantes e as seguintes questões: 
1. 0 que você entende por humanização no atendimento hospitalar?

2. Qual é a reação do(a) paciente à situação da internação?

3. 0 que você achou da visita dos palhaços doutores?

4. Como foi a reação do(a) paciente a essa visita?

5. Você observou mudanças no(a) paciente após a visita do Projeto Trupe Sorriso?

6. Você acha importante a visita dos palhaços doutores na pediatria? Por quê?

As entrevistas foram registradas via gravador de áudio. 0 término da coleta de dados se deu por saturação, ou seja, segundo Fontanela ${ }^{12}$, quando já não se constataram elementos novos para subsidiar o estudo.

Os dados foram submetidos à Análise de Conteúdo de Bardin ${ }^{13}$, com identificação de categorias temáticas, pautadas pela recorrência de conteúdos e sua intensidade nas falas, o que as tornaram relevantes (núcleo de sentidos que compõem uma comunicação). A Análise de Conteúdo possibilitou o agrupamento das percepções das entrevistadas em relação à assistência humanizada, constituindo as categorias temáticas do estudo. Minayo ${ }^{14}$ aponta que a Análise de Conteúdo tem duas funções; a que se aplica a este trabalho é a de que a referida técnica “diz respeito à descoberta do que está por trás dos conteúdos manifestos, indo além das aparências do que está sendo comunicado".

A pesquisa foi aprovada em 14 de dezembro de 2017 pela Comissão de Ética da Unidade Clínica de Pesquisa do Hospital de Messejana Dr. Carlos Alberto Studart Gomes, via e Plataforma Brasil, sob o Parecer Consubstanciado n. 2.525.407/2018, cumprindo todas as determinações da Resolução n. 466/2012 ${ }^{15}$, do Conselho Nacional de Saúde (CNS).

\section{Os efeitos \\ terapêticos da arte têm sido reconhecidos há alguns séculos...}

\section{RESULTADOS E DISCUSSÃO}

\section{Caracterização dos sujeitos}

Para maior compreensão da realidade dos sujeitos, faz-se necessária a apresentação de aspectos demográficos e socioeconômicos das mães e de seus filhos internados:

1. Local de residência: dentre as 12 mães entrevistadas, 8 residiam na zona rural e 4 eram da Cidade de Fortaleza;

2. Nivel de escolaridade: 5 tinham Ensino Fundamental completo; 4 tinham Ensino Fundamental incompleto; 3 tinham Ensino Médio completo; e nenhuma tinha Ensino Superior completo;

3. 0cupação: 5 mães trabalhavam na agricultura; 4 eram do lar; e 3 tinham empregos formais.

Houve predomínio de mães vivendo com o pai da criança (8), que permaneciam 24 horas por dia no hospital; as demais (4) revezavam os cuidados com seus companheiros, por terem outros filhos e por serem trabalhadoras formais.

Quanto aos dados clínicos, todas eram mães biológicas. 0 diagnóstico predominante das crianças (9) foi necessidade de cirurgia ou procedimento cirúrgico anterior.

A partir dos resultados levantados se identificaram 3 categorias temáticas: a) Hospitalização infantil; b) Humanização do atendimento hospitalar; e c) Visita do Projeto Trupe Sorriso.

A discussão das categorias é ilustrada com as falas das mães participantes, usando, para identificá-las, a letra " $M$ " de mãe, seguida pela numeração arábica correspondente à ordem de adesão à pesquisa (M1, M2 ... M12).

\section{Hospitalização infantil}

Os resultados apresentados trouxeram aspectos relativos à hospitalização infantil, os quais foram considerados pelas mães um sofrimento tanto para elas quanto, principalmente, para seus filhos. Essas mães, devido à internação de seus filhos, necessitavam permanecer na instituição hospitalar. Nesse acompanhamento, um aspecto destacado nas falas acerca da rotina hospitalar foi a situação da criança diante da hospitalização:

Ele não está se sentindo muito bem, estou percebendo, ele não tá do jeito que é em 
casa, em casa ele brinca, aqui ele não brinca e chora muito, fica triste, chorando, não come direito [...] eu acho que ele tá sentindo falta da irmã. (M3)

No primeiro dia ele só fica chorando, querendo ir pra casa, querendo o pai dele, porque ele é muito apegado ao pai [...] saudade da casa, do avô, dos brinquedos. (M8)

Dentre os principais fatores de estresse identificados temos: a) afastamento e separação da criança de seus principais contextos de vida (família, escola, grupo de amigos); b) alterações significativas em suas rotinas; e c) percepção de ameaça perante o desconhecido, a dor e o desconforto associados a situação clínica, tratamentos e exames ${ }^{16}$.

Percebe-se que o afastamento da convivência familiar causa sofrimento às crianças internadas - a saudade dos entes queridos afeta o humor e dificulta o tratamento rápido e eficaz da criança.

A criança enfrenta dificuldades com experiências dolorosas e desagradáveis, portanto, o apoio daqueles que assistem à criança é essencial para a adaptação ao âmbito hospitalar e aos tratamentos, pois se acredita que a atuação diferenciada com a criança contribui em seu cotidiano de internação.

\section{Humanização do atendimento hospitalar}

As manifestações dos sujeitos levaram à identificação de várias ideias centrais relativas ao entendimento das mães acerca do atendimento humanizado no hospital, dando origem a dois discursos coletivos: a) qualidades esperadas do profissional; e b) entendimento de humanização hospitalar.

\section{Qualidades esperadas do profissional}

Eu entendo ser mais humano, o profissional ser mais humano com o paciente, que é o que ele mais tá precisando no momento, amor ao próximo, e o que eu entendo é isso. (M12)

Eu acho que é assim... você ser tratado bem, ter as medicações na hora, as meninas (enfermeiras e técnicas de enfermagem) saberem falar direito com a gente, explicarem tudo. (M2)

Devido à origem e ao sentido intrínseco desse termo, as entrevistadas conseguiram associar a ideia de cuidado humanizado com o atendimento que observa e tenta entender mais o lado do paciente. Tal percepção vem ao encontro da perspectiva assistencial holística e da definição de saúde global, na medida em que os discursos associam a atenção ao paciente à ideia de que todos merecem receber um atendimento igual e que atenda às suas necessidades (aspectos físicos, psicológicos, espirituais).

Apesar do comportamento de alguns membros da equipe ser percebido pelas mães como ofensivo, os sentimentos ambivalentes em relação a esses profissionais se fazem presentes, ou seja, elas sofrem com as ofensas e, ao mesmo tempo, sentemse agradecidas por estarem salvando a vida de seus filhos:

Certo que às vezes eu não tiro a razão delas, não, têm algumas delas aqui que tratam a gente mal, com ignorância, mas a gente não sabe o que elas estão passando [...] tem que entender o lado delas também. (M5)

Podem me tratar com ignorância, graças a Deus meu filho está recebendo tratamento e tem gente para cuidar dele [...] tem tanta criança que precisa, tenho é que agradecer. (M8)

Os diálogos evidenciam que, mesmo percebendo ofensas dos profissionais da saúde, as mães se sentem agradecidas por terem a possibilidade de realizar o tratamento de seus filhos e reconhecem que profissionais capacitados proporcionam cuidado e bem-estar a eles.

\section{Entendimento de humanização hospitalar}

As ideias de algumas mães sobre o atendimento humanizado no hospital se mostram um tanto vagas, gerando dúvidas acerca do(a) conhecimento/ familiaridade com tal terminologia. Dentre as 12 mães entrevistadas, 6 não sabiam responder o que era humanização hospitalar, 3 já tinham ouvido falar

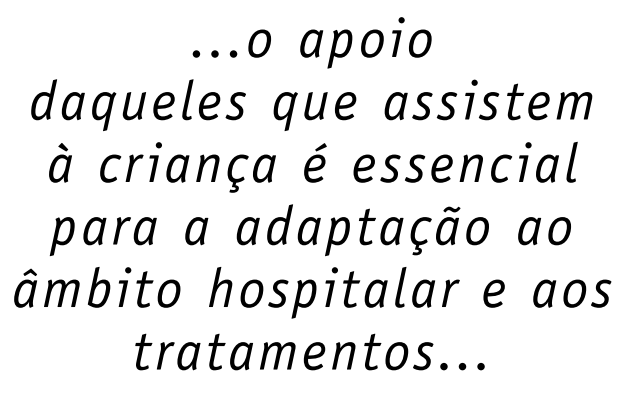

...o apoio daqueles que assistem à criança é essencial para a adaptação ao tratamentos... 
sobre o assunto e 3 explicaram com suas palavras o que conheciam sobre o assunto, sempre relacionando o tratamento do(a) profissional para com elas.

Para Ribeiro (2015) ${ }^{17}$, humanizar também é consequência de atitudes que buscam tornar o próprio ser humano mais amável, bondoso e compreensivo. Humanizar é trazer à tona o que nos faz humanos, destacando nossa capacidade de colocarmo-nos no lugar do outro.

Sob essa perspectiva, o entendimento da humanização da assistência, dentre as mães em questão, relaciona-se à capacidade de abordar o paciente de modo holístico e igualitário ${ }^{18}$. As atitudes que conferem um caráter humanizado à assistência englobam o estilo de comunicação adotado, ao passo que 0 atendimento não humanizado se traduz em atitudes que valorizam as regras hospitalares, a falta de atenção e a baixa empatia por parte dos profissionais da saúde.

A humanização da assistência visa garantir a autonomia e dignidade do paciente, assim, os profissionais da saúde o tratam com respeito, carinho e amor, respeitando seus limites, oferecendo orientações sobre sua patologia e os procedimentos adotados e cuidando não só da doença, mas da pessoa - o que demanda um olhar diferenciado ${ }^{19: 10}$.

Deve-se considerar, ainda, que a humanização foi abordada pelas mães de modo superficial e somente no nível da terminologia - ou seja, fazse necessário um aprofundamento nas instituições e nos serviços de saúde, com maior esclarecimento à população sobre a PNH, como forma de empoderar e proporcionar autonomia (a)os beneficiários das políticas públicas de saúde.

\section{Visita do Projeto Trupe Sorriso}

Para fortalecer a luta em defesa do atendimento humanizado, muitos autores têm realizado estudos sobre a contribuição do bom humor na recuperação dos pacientes acometidos pelas mais variadas patologias. Acredita-se que o riso pode trazer grandes benefícios, sem contar as vantagens psicológicas de manter-se bem-humorado(a) e o fato de que pessoas mais estabilizadas emocionalmente tendem a superar maus momentos de modo mais leve ${ }^{16}$. Dessa maneira, a visita do Projeto Trupe Sorriso a setor de pediatria proporcionou momentos de alegria e descontração tanto às crianças quanto às mães.

É muito bom, a pessoa estar ali naquele lugar, se achando sozinha, e de repente surgem pessoas para dar uma animada, fazer a gente rir [...] é sempre bom. (M1)

Gostei muito, a gente também precisa de uma distração [...] eu acho legal, eu acho que traz mais alegria para as crianças e para nós também [risos], eu fiquei morta de alegre também, tira mais aqueles pensamentos negativos da cabeça da gente, eu adorei. (M5)

Várias pesquisas abordam os benefícios do humor na recuperação de pacientes; Caires ${ }^{16}$ aponta que 0 riso aumenta a secreção de endorfina (conhecida como hormônio do prazer), que relaxa as artérias, melhora a circulação e beneficia o sistema imune, também estimulando a produção de adrenalina, o que ocasiona mais irrigação nos tecidos que recebem mais oxigênio e, dessa maneira, eles apresentam maior eficiência. 0 bom humor aumenta, ainda, a capacidade de resistir à dor:

Ela melhorou bastante, tanto que as brincadeiras que ela tinha parado de fazer ela retornou, de soltar beijinho, ela reagiu muito bem. (M1)

Ficou mais alegre, ele esqueceu mais de casa, porque ele estava chorando muito. Brincou, antes tinha uma moça com uns brinquedos, agora não tem, então ele fica entediado, ontem com vocês ele fez a festa, era vocês saindo e ele indo atrás, nem se lembrou de mim [risos]. (M11)

Torquato $^{18}$ esclarece que, decerto, a ausência de relação humanizada entre profissionais assistencialistas, a criança e a mãe pode repercutir de maneira negativa na recuperação clínica do

\section{Acredita-se que o riso pode trazer grandes beneficios...}




\section{...não são necessários grandes investimentos para desencadear um processo de humanização no ambiente hospitalar.}

pequeno paciente, prolongando seu período de permanência hospitalar, acentuando suas fragilidades e comprometendo a assistência prestada.

Também foi possível identificar a comunhão dos profissionais de saúde em torno de uma causa compartilhada. A arte, devido a seu potencial de promover a experiência estética, seria capaz de estabelecer pontes que conectam o singular com o compartilhado, ampliando a sensação de união e pertencimento e fazendo com que as relações se tornem mais próximas, de modo que o vínculo se estabeleça não só por conta do adoecimento da criança, mas da empatia e do respeito para com o próximo.

\section{CONCLUSÃO}

0 cuidar humanizado implica, por parte do cuidador, a compreensão e a valorização da pessoa humana enquanto sujeito histórico e social. Para tanto, deve-se considerar, acima de tudo, que não são necessários grandes investimentos para desencadear um processo de humanização no ambiente hospitalar. É primordial que haja sensibilização quanto à problematização da realidade concreta, a partir da equipe multidisciplinar.

A humanização defende o restabelecimento da dignidade humana, muitas vezes comprometida nas interações no setor saúde. Uma prática reducionista de cuidado, pautada exclusivamente pela lógica tecnocientífica e pelo automatismo resultante de certa forma de organização do trabalho, seriam fatores a contribuir com a desqualificação das relações entre os sujeitos. Nesta pesquisa, a arte se mostrou uma poderosa ferramenta para ampliar o horizonte de olhares e promover o uso de outros canais de percepção do mundo.

No caso que serviu de base para este estudo, a arte pareceu ser o melhor caminho para transformações objetivas e subjetivas, criando novos símbolos para as pessoas que participaram das vivências propostas, além de refletir e instruir mudanças de intenções e atitudes no cotidiano dos indivíduos.

\section{CONTRIBUIÇÃO DAS AUTORAS}

Francisca Leyla da Silva Morais contribuiu com a realização da pesquisa, o delineamento do estudo e a redação do manuscrito. Angélica Maria Barbosa, Fátima Maria Coelho Bezerra Bastos e Renata Lima da Costa contribuíram com a redação e revisão crítica do manuscrito.

\section{REFERÊNCIAS}

1. Bravo MI, Mota AE, Lima R, organizers. Política de saúde no Brasil. 4. ed. São Paulo: Cortez; 2018.

2. Bravo MI. Serviço social e reforma sanitária: lutas sociais e práticas profissionais. São Paulo: Cortez; 2015.

3. Brasil. Política Nacional de Normalização: atenção hospitalar. Brasília (DF): Ministério da Saúde; 2013. (Cadernos HumanizaSUS, v. 3).

4. Silva DC, Krüger TR. Parâmetros para a atuação de assistentes sociais na política de saúde: o significado no exercício profissional. Temporalis [serial on the internet]. 2018 [cited 2020 Nov 13];18(35):265-88. Available from: file:///D:/19578-Texto $\% 20$ do $\% 20$ artigo-59300-1-10-20180710.pdf

5. Brasil. Resolução n. 553, de 9 de agosto de 2017. Aprova a atualização da Carta dos Direitos e Deveres da Pessoa Usuária da Saúde, que dispõe sobre as diretrizes dos Direitos e Deveres da Pessoa Usuária da Saúde. Brasília (DF): Conselho Nacional de Saúde; 2017.

6. Brasil. A experiência da diretriz de Ambiência da Política Nacional de Humanização - PNH. Brasília (DF): Ministério da Saúde; 2017.

7. Matos MC. Considerações sobre atribuições e competências profissionais de assistentes sociais na atualidade. Serv Soc Soc [serial on the internet]. 2015 [cited 2020 Nov 13];(124):678-98. Available from: https://www.scielo.br/pdf/sssoc/n124/01016628-sssoc-124-0678.pdf

8. Alves FL, Mioto RC, Gerber LM. A política nacional de humanização e o serviço social: elementos para o debate. Serviço Social e Saúde [serial on the internet]. 2015 [cited 2020 Nov 13];(6):35-52. Available from: https://periodicos.sbu.unicamp.br/ ojs/index.php/sss/article/view/8634944 
9. Sahão BP. Aspectos sociais da arte na sociedade capitalista: uma reflexão sobre a função social da arte nas relações humanas [monograph on the internet]. São Paulo: Universidade de São Paulo; 2014 [cited 2020 Nov 13]. Available from: http:// celacc.eca.usp.br/sites/default/files/media/tcc/ artigo tcc final sahuo.pdf

10. Fischer E. A necessidade da arte. Rio de Janeiro: Zahar; 1983.

11. Digiácomo MJ, Digiácomo IA. Estatuto da Criança e do Adolescente anotado e interpretado. 7 ed. Curitiba: Ministério Público do Estado do Paraná; 2017.

12. Minayo MC. Amostragem e saturação em pesquisas qualitativa: consensos e controvérsias. Revista Pesquisa Qualitativa [serial on the internet]. 2017 [cited 2020 Nov 13];(5):1-12. Available from: https://edisciplinas.usp.br/pluginfile.php/4111455/ mod resource/content/1/Minayosaturacao.pdf

13. Bardin L. Análise de conteúdo. Lisboa: Ed. 70; 2016.

14. Deslandes SF, Otávio CN, Gomes R, Minayo MC. Pesquisa social: teoria, método e criatividade. 34. ed. Petrópolis (RJ): Vozes; 2015.

15. Brasil. Resolução n. 466, de 12 de dezembro de 2012 [document on the internet]. Brasilia (DF): Conselho Nacional de Saúde; 2012 [cited 2020 Nov 13]. Available from: http://conselho.saude.gov.br/ resolucoes/2012/Reso466.pdf

16. Caires S, Esteves CH, Correia S, Almeida I. Palhaços de hospital como estratégia de amenização da experiência de hospitalização infantil. Psico USF [serial on the internet]. 2014 [cited 2020 Nov 13];(19):377-86. Available from: https://www. scielo.br/scielo.php?script $=$ sci arttext $\&$ pid $=S 1413$ $82712014000300002 \& \operatorname{lng}=p t \& t \operatorname{lng}=p t$

17. Ribeiro I, Silveira MG. Humanização hospitalar no Sistema Único de Saúde. Revista Interdisciplinar Ciências e Saúde [serial on the internet]. 2015 [cited 2020 Nov 13];(2):19-24. Available from: https:// revistas.ufpi.br/index.php/rics/article/view/2040

18. Torquato IM, Collet NC, Dantas MS, Jonas MF, Trigueiro JV, Nogueira MF. Assistência humanizada à criança hospitalizada: percepção do acompanhante. Rev Enferm UFPE On Line [serial on the internet]. 2013 [cited 2020 Nov 13];7(9):5541-9. Available from: https://periodicos.ufpe.br/revistas/ revistaenfermagem/article/viewFile/13672/16561

19. Araújo EJ, Ponte KM, Araújo LM, Farias MS. Satisfação dos familiares com humanização da assistência em UTI. Sanare (Sobral, Online) [serial on the internet]. 2019 [cited 2020 Nov 13];18(1):611. Available from: https://sanare.emnuvens.com. br/sanare/issue/view/39

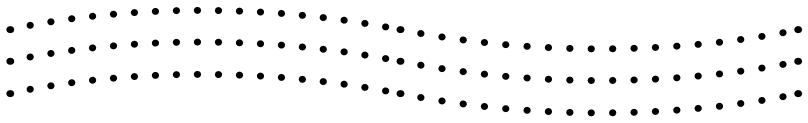

$\ldots \ldots \ldots \ldots \ldots \ldots \ldots \ldots \ldots \ldots \ldots \ldots \ldots \ldots \ldots$

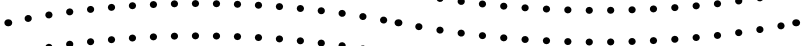

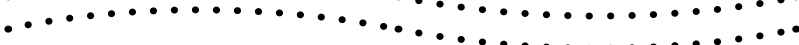

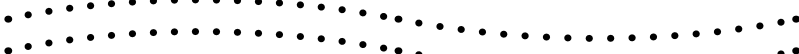
$\ldots \ldots \ldots \ldots \ldots \ldots \ldots \ldots \ldots \ldots \ldots \ldots \ldots \ldots \ldots \ldots$

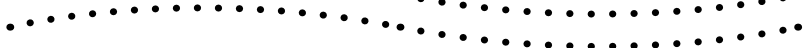

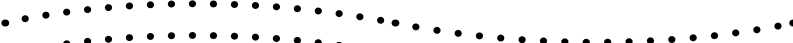
$\cdots \cdots \cdots$

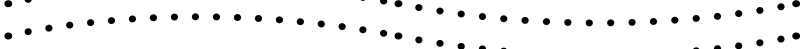

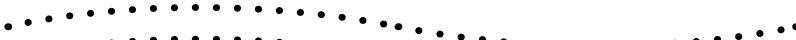
$\ldots \ldots \ldots \ldots \ldots \ldots \ldots \ldots \ldots$ $\ldots \ldots \ldots \ldots \ldots \ldots \ldots \ldots \ldots \ldots \ldots$ ... 